microscopically that the degree of dilatation of the pyloric canal used $(4 \mathrm{~cm})$ causes any morphological change in the mucosa or the musculature of the wall. On the other hand, clinical, radiological, and endoscopic evidence shows that the intricate mechanism of the antropyloroduodenal channel is not destroyed, as, for example, in pyloroplasty. Bile reflux was not seen clinically, and no patient developed a postoperative gastric ulcer. We believe that patients return to normal feeding earlier and that the incidence of undesirable sequelae is lower after TV and PD compared with patients in whom one of the conventional drainage procedures have been performed. Further study will be required before any real comparison can be made with the results after PGV.

Goligher, ${ }^{12}$ reporting on a series of 117 patients who underwent PGV and were followed up for five to eight years, recorded a similar overall result in terms of Visick gradingnamely, $75^{\circ}{ }^{\circ}$ in categories I plus II. As compared with vagotomy and drainage he concluded that PGV was followed by less dumping and diarrhoea but did not offer appreciably better overall results. Mackey et al, ${ }^{13}$ reporting on a series of 115 patients who had been treated by PGV and followed up for one to five years in a district general hospital, recorded a satisfactory result in $91 \%$. Their incidence of recurrent ulceration was $5 \cdot 1^{\circ}{ }_{0}$ after an average interval of two years and that of new gastric ulceration $2.5^{\circ} \%$ after an average of four years.

PGV is a technically exacting procedure attended by anxieties related to the vascularity of the lesser curvature of the stomach. ${ }^{1+15}$ By contrast, TV and PD is both safe and economic in terms of time and manpower and complies with Dragstedt's view $^{16}$ that "the operation for elective duodenal ulcer surgery must be safe in the hands of the average surgeon using a technique that is acceptably effective."

We are indebted to our surgical and nursing colleagues who have contributed to this study and to Dr D McEwan Jenkinson and Dr G E Thomson, of the Hannah Research Institute, for their collaboration in experimental work. We thank Mrs Helen Graham for secretarial support, and acknowledge a grant from the Ayrshire and Arran Health Board.

\section{References}

${ }^{1}$ Dragstedt, L R, and Camp, E H, Gastroenterology, 1948, 11, 460

${ }^{2}$ McKelvey, S T D, British fournal of Surgery, 1970, 57, 741.

${ }^{3}$ Johnston, D, and Wilkinson, A R, British fournal of Surgery, 1970, 57, 289.

4 Baron, J H, and Spencer, J, Surgical Clinics of North America, 1976, 56, 1297.

${ }^{5}$ Green, R, Spencer, A, and Kennedy, T, British fournal of Surgery, 1978, 65, 161.

'MacKenzie, I, personal communication.

7 Thomson, G, personal communication.

${ }^{8}$ Jenkinson, D, and Stewart, J, personal communication.

9 Tanner, N C, Surgical Clinics of North America, 1976, 56, 1349.

10 Burge, H, British Medical fournal, 1971, 1, 172

${ }^{11}$ Kirk, R M, Proceedings of the Royal Society of Medicine, 1975, 68, 179.

${ }^{12}$ Goligher, J C, et al, British fournal of Surgery, 1978, 65, 145.

${ }_{13}$ Mackey, D A, et al, British fournal of Surgery, 1979, 66, 39.

${ }_{14}$ Moore, F P, et al, British Medical fournal, 1975, 4, 328.

${ }_{15}$ Heffernan, S J, British Medical fournal, 1976, 1, 398.

${ }^{16}$ Dragstedt, L R, in Vagotomy on Trial, ed A G Cox and J AlexanderWilliams. London, Heinemann, 1973.

(Accepted 20 April 1979)

\title{
Proximal gastric vagotomy, fundoplication, and lesser-curve necrosis
}

\author{
T KENNEDY, P MAGILL, G W JOHNSTON, T G PARKS
}

British Medical fournal, 1979, 1, 1455-1456

\section{Summary and conclusions}

Out of 400 patients who underwent proximal gastric vagotomy (PGV), three developed lesser-curve necrosis (LCN) leading to perforation within the first seven days. In each case diagnosis was delayed but the patient survived after a second operation. In each an associated Nissen fundoplication had been carried out; we used the combined operation in only 33 patients. Delayed LCN occurred in a patient who had undergone splenectomy at the time of the PGV and in a fifth patient treated elsewhere who had also undergone fundoplication.

These findings indicate that early postoperative gastric distension with gas, not readily voided after fundoplication, may aggravate local vascular factors and predispose to LCN. We suggest that PGV combined with fundoplication may be dangerous.

The Royal Victoria Hospital, Belfast BT12 6LA

$T$ KENNEDY, MS, FRCS, consultant surgeon

P MAGILL, MB, FRCS, senior surgical registrar

G W JOHNSTON, MCH, FRCs, consultant surgeon

$T$ G PARKS, $M C H$, FRCS, reader in surgery

\section{Introduction}

Since 1974 sporadic cases of lesser-curve necrosis (LCN) after proximal gastric vagotomy (PGV) have been reported. ${ }^{1-5}$ Necrosis and perforation were fatal in three of the first seven reported cases. The rarity of LCN is shown by Johnston's world-wide survey ${ }^{6}$ of 5539 PGVs, in which five deaths occurred from this cause. Though rare, $\mathrm{LCN}$ is possibly the most important single cause of death after PGV, which is otherwise a safe operation, with a mortality of $0.2 \%{ }^{6}{ }^{6} \mathrm{~A}$ variant of the condition, in which a lesser-curve ulcer appears within a week or two of PGV, has also been described. ${ }^{7-9}$

The precise cause of LCN is not known. Uraemia, excessive use of diathermy, and inexperience of the surgeon have all been blamed. We have recently encountered three instances each associated with Nissen's fundoplication.

\section{Case reports}

Case 1-A man aged 37 with duodenal ulcer and hiatus hernia underwent a straightforward PGV and fundoplication. A few branches of the right gastroepiploic vessels were ligated. The lesser curve was not reperitonealised. On the fifth day sudden pain occurred in the left chest and shoulder and pulmonary embolus was suspected. On the sixth day there were signs of peritonitis, and at reoperation a necrotic area was found just below the fundoplication. This was sutured. He made an uninterrupted recovery and remained well one year later.

Case 2-A man aged 42 with duodenal ulcer and hiatus hernia underwent PGV and fundoplication, and the lesser curve was 
reperitonealised. Three days later sudden left chest pain was thought to be due to pulmonary embolus. On the fourth day there were signs of peritonitis. Reoperation showed necrosis of the lesser curvature 3 $\mathrm{cm}$ in diameter, which was sutured. He made a satisfactory recovery and remained well eight months later.

Case 3-A man aged 54 with gall stones, duodenal ulcer, and hiatus hernia was treated by cholecystectomy, PGV, and fundoplication. Operation was difficult owing to obesity, and the lesser curve was not reperitonealised. On the fifth day he developed acute gastric dilatation, which did not respond to intubation. On the sixth day reoperation disclosed a $1-\mathrm{cm}$ perforation high on the lesser curvature just below the fundoplication. After simple suture recovery was uncomplicated.

These three patients had much in common. All were men aged 37-54. All had chronic duodenal ulcer and hiatus hernia and were in other respects healthy. None had renal failure. Symptoms appeared within five days and were thought initially to be due to pulmonary embolism in two and acute gastric dilatation in one. In each case reoperation was delayed for 24 hours. The perforations were readily closed by suture, and all three patients survived.

Reports indicate that gastric ulcer occurring in the early postoperative period may be an incomplete form of LCN and we have seen two cases of this.

Case 4-A man aged 60 underwent PGV for duodenal ulcer. Operative damage to the spleen led to splenectomy. Five morths later massive haematemesis required operation; a high posterior wall gastric ulcer $8 \mathrm{~cm}$ in diameter was found and treated successfully by gastrectomy.

Case 5-A man aged 49 underwent PGV and fundoplication at another hospital. After three weeks he was readmitted there with chest pain diagrosed as pulmonary embolus and treated with anticoagulants. Three weeks later he was admitted with severe haematemesis Operation disclosed massive necrosis of the lesser curvature, which was sutured, and he did well postoperatively.

\section{Discussion}

PGV, in which the left gastric artery is divided, inevitably reduces the blood flow to the lesser curvature. Some of the vessels of the lesser curve are end arteries, ${ }^{10}$ which could enhance its vulnerability. Systemic factors may be important, including hypertension, advanced age, obstructive airways disease, and uraemia. Uhlschmid et al ${ }^{11}$ reported two fatal cases of LCN in 12 patients with advanced renal disease who underwent PGV. None of our patients had gross systemic disease. Surgical inexperience and diathermy trauma are not likely to explain our three cases of LCN. Our first case occurred after more than 300 PGVs had been performed, and though we do not absolutely ban the use of diathermy, we use it only sparingly. Reperitonealisation of the lesser curve has been recommended as a prophylactic measure. ${ }^{49}$ One of us has used reperitonealisation routinely during the past four years, and it was done in case 2.

The remarkable coincidence in our experience was the association with Nissen's fundoplication. We have now carried out PGV in over 400 patients in 10 years. Our only case of LCN in patients in whom we have not performed fundoplication has been case 4 , the probable cause being additional devascularisation caused by splenectomy. In one of the fatal cases of Uhlschmid et al splenectomy was also done. ${ }^{11}$ Among our 33 patients who underwent combined PGV and fundoplication three cases of LCN occurred. The patient in case 5 also underwent the combined operation, but we do not know the number of such operations done at the hospital where this patient's primary surgery was carried out One patient with LCN, reported on by Kalsbeek, ${ }^{12}$ had a fundoplication to protect an accidental oesophageal injury; this patient also had severe arterial disease.

Why should fundoplication apparently predispose to LCN ? We had thought that it might complement reperitonealisation of the lesser curvature. Why should the lesser-curve blood supply be diminished, since we did not divide any short gastric arteries and were most careful not to plicate too tightly? If fundoplication does not diminish the blood supply, how does it cause necrosis? We believe that gastric distension is the under- lying cause. In the first few days after fundoplication swallowed air cannot easily be expelled by belching. We normally leave a nasogastric tube in place for 48 hours after operation, and this was done in all our cases. In case 3 after the tube was removed enormous gastric distension, seen on $x$-ray films, preceded the development of necrosis. Such distension could stretch and compress lesser-curve vessels and be the factor precipitating necrosis.

After PGV the fundus of the stomach is so well mobilised that it is extremely simple to perform fundoplication when the patient has oesophageal reflux. Adding PGV to fundoplication has been advocated even in the absence of duodenal ulcer ${ }^{13}$ but our experience suggests that this combination may be dangerous. If our hypothesis is correct tubeless surgery may be dangerous and it might be wise to leave a gastrostomy tube in the stomach for seven to 10 days when it is deemed necessary to combine PGV and fundoplication.

Although well known, $\mathrm{LCN}$ is rare and not easily recognised. It usually presents between the third and seventh postoperative days and need not be fatal if treated promptly.

\section{References}

${ }^{1}$ Newcombe, J F, British Medical fournal, 1973, 1, 610.

${ }^{2}$ Hall, R, Summers, G A C, and Green, M A, British Medical fournal, $1974,3,806$

3 Wylie, J H, British Medical fournal, 1974, 2, 561.

${ }^{4}$ Halvorsen, J F, et al, British Medical fournal, 1975, 2, 590.

5 Brodie, S W, British Medical fournal, 1975, 3, 229.

6 Johnston, D, British Medical fournal, 1975, 4, 545.

7 Lambert, R, et al, Archives Françaises des Maladies de l'Appareil Digestif 1976, 65, 41 .

${ }^{8}$ Cuilleret, J, et al, Nouvelle Presse Médicale, 1977, 6, 1843.

${ }^{9}$ Croft, R J, Archives of Surgery, 1978, 113, 206.

${ }^{10}$ Piasecki, C, Annals of the Royal College of Surgeons of England, 1977, 59, 476.

${ }^{11}$ Uhlschmid, G, Sauberli, H, and Largiader, F, Helvetica Chirurgica Acta, 1975, 42, 547.

12 Kalsbeek, H L, Archivum Chirurgicum Neerlandicum, 1977, 89, 101.

13 Jones, N A G, and Anders, C J, Annals of the Royal College of Surgeons of England, 1979, 61, 48

(Accepted 18 April 1979)

ONE HUNDRED YEARS AGO At the last business meeting of the King and Queen's College of Physicians in Ireland, Sir Dominic Corrigan, Bart, moved the suspension of the standing orders of the College relative to the proposing and election of Honorary Fellows, in order to propose "that the distinction of honorary fellowship of the College be corferred on Surgeon-Major James Henry Reynolds, $A M D$, in appreciation of his memorable services in the action at Rorke's Drift, Zululand, on the night of the 22nd of January, 1879.' The motion was seconded by Professor Sinclair and carried unanimously. On the 9 th instant, a special meeting of the College was held, at which Surgeon-Major Reynolds was duly elected. While the War-Office authorities, although publicly and officially recognising Surgeon-Major Reynolds's gallant services, have as yet been conten with rewarding him by a promotion which, in the ordinary course of events, would have taken place in fourteen months, it will probably afford some slight consolation to the officers of the Army Medica Department that, if such services as Dr Reynolds's be not deemed worthy of the recognition and rewards his equally gallant but not more deserving "combatant" co-defenders of the post justly received, the medical corporate bodies will not be behindhand in awarding them, when merited, the highest honours in their power. Such treatment of the officers of the Army Medical Department is, to say the least of it, not politic at the present time. The University of Dublin, of which Surgeon-Major Reynolds is a graduate, also intend to honour him with the degree of LLD. The last honorary fellowship that the College of Physicians conferred was also on an officer of the Army Medical Department-Surgeon-Major T M Bleckley, CB-in 1874, for his services during the Ashantee war. Neither of these gentlemen is a licentiate of the College. (British Medical fournal, 1879.) 